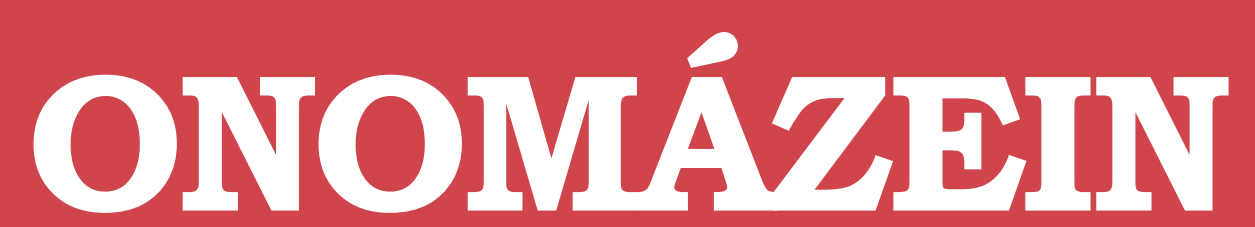

Revista semestral de lingüística, filología y traducción
PONTIFICIA UNIVERSIDAD CATÓLICA DE CHILE CATOLICA DE CHILE
FACULTAD DE LETRAS

\title{
Carencia de vivienda en la Ciudad de Buenos Aires: análisis sociodiscursivo crítico de sus causas y consecuencias
}

Lack of housing in Buenos Aires City:

a critical sociodiscursive analysis of its

causes and consequences

\section{Mariana Carolina Marchese}

Universidad de Buenos Aires / CONICET

Argentina

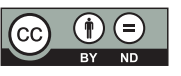

Mariana Carolina Marchese: Departamento de Letras, Facultad de Filosofía y Letras, Universidad de Buenos Aires, Argentina / Consejo Nacional de Investigaciones Científicas y Técnicas, Argentina.

| Correo electrónico: marianacmarch@yahoo.es 


\section{Resumen}

Muchos de los habitantes de la Ciudad de Buenos Aires atraviesan serias dificultades habitacionales, que se complejizaron durante el siglo XXI al punto tal que la Legislatura de la Ciudad prorrogó sistemáticamente el estado de emergencia habitacional. En ese contexto, el objetivo de este trabajo es dar cuenta de las causas profundas y de las consecuencias so- ciales relacionadas con dicha problemática, puesto que esta posee un fuerte impacto simbólico sobre la identidad de quienes la padecen. El marco teórico es el Análisis Crítico del Discurso, la metodología es cualitativa y el corpus está compuesto por historias de vida y por discursos del Gobierno de la Ciudad sobre la denominada "cuestión habitacional".

Palabras clave: problemática habitacional urbana; impacto simbólico; Análisis Crítico del Discurso.

\section{Abstract}

Many of Buenos Aires City's inhabitants undergo serious housing difficulties. During the 21st century these difficulties have become more and more complex, to the point that the City's Legislature has systematically extended the state of housing emergency. In this context, the aim of this paper is to explain the deep causes and the social consequences involved in the housing is- sue, as it has a strong symbolic impact on the identities of those who undergo it. The theoretical frame for this work is Critical Discourse Analysis, its methodology is qualitative and the corpus consists of life histories and City's Government speeches on the so-called "housing issue".

Keywords: urban housing issue; symbolic impact; Critical Discourse Analysis. 


\section{Introducción}

En el año 2004, comencé a trabajar en el equipo argentino que integra la Red Latinoamericana de Análisis Crítico del Discurso de la pobreza (REDLAD). Este equipo es interdisciplinar y su tema central de investigación es la pobreza en la Ciudad Autónoma de Buenos Aires (CABA) y en el Conurbano bonaerense. La REDLAD se comenzó a formar hacia el año 2001 y busca hacer visibles las causas y las consecuencias de los procesos de exclusión que se produjeron en Latinoamérica, especialmente, durante la década del noventa y después de ella.

Teniendo presente que el discurso posee un rol esencial dentro de los fenómenos sociales y bajo la impronta de quienes pensaron el análisis del discurso desde un punto de vista crítico (Fairclough, 1992; Van Dijk, 1993; Wodak, 2000), Ios fundadores de la red (García da Silva, 2007; Pardo Abril, 2007; Pardo, 2008a, 2011; Montecino, 2010) la crearon con los siguientes objetivos: intercambiar resultados de investigación, formar a nuevos investigadores y desarrollar metodologías lingüísticas de análisis que puedan dar cuenta del uso del español y del portugués (Resende y Marchese, 2011; García da Silva y D’Angelo, 2011). Todo ello con el fin de que los estudios realizados sean herramientas para disciplinas afines e instrumentos para apoyar la discusión sobre la elaboración de políticas públicas que involucren a sujetos en situación de pobreza.

Las investigaciones que abordé en el marco de ese equipo, así como mi experiencia laboral durante el período 1999-2004 en dos programas del Gobierno de la Ciudad Autónoma de Buenos Aires (GCABA) especializados en la problemática habitacional, me permitieron observar cómo esta se fue agudizando, mientras que fracasaban sistemáticamente los programas del GCABA im- plementados para revertirla. Por ello, el objetivo específico de este trabajo es analizar lingüísticamente la construcción de representaciones discursivas (Pardo, 2011) en torno a la categoría discursiva Espacio habitacional (por ejemplo, vivienda, casa, parador, hogar de tránsito y hotel) en discursos del GCABA referidos a la problemática habitacional y en historias de vida de habitantes de la CABA que atraviesan esa problemática. Mediante el estudio de ambos corpus, se reflexionará sobre la intersección sociodiscursiva entre ellos, de modo tal que esa reflexión evidencie, a través de datos lingüísticos concretos, las diferencias y las similitudes entre las representaciones vinculadas a la categoría Espacio habitacional construidas en ambos discursos con el fin de que este análisis colabore a explicar las causas profundas y las consecuencias sociales relacionadas con la "cuestión habitacional".

\section{Un estudio sociodiscursivo sobre la problemática habitacional de la CABA}

En forma paulatina, pero sostenida, el déficit habitacional de la CABA se fue profundizando con el avance del orden global posmoderno. Una característica que define este orden radica en que la categoría Espacio se convirtió en un elemento central de las vivencias cotidianas (Pardo, 2008b). En palabras de Wacquant, “... Ia reconfiguración actual del capitalismo implica no solo un vasto reacomodo de las empresas y de los flujos económicos, de los empleos y de las personas en el espacio sino también una revolución total de la organización y de la experiencia del espacio mismo" (2007: 195) ${ }^{1}$

En ese contexto, en Latinoamérica, uno de los derechos sociales más vulnerados fue el del acceso a la vivienda (Pradilla Cobos, 2010; Demajo Meseguer, 2011; Moura, 2011). Esa situación,

1 Los subrayados son del original.

2 Este derecho está contemplado tanto en el derecho internacional (Declaración Universal de Derechos Humanos y Pacto Internacional de Derechos Económicos, Sociales y Culturales) como en las constituciones de la Nación Argentina y de la CABA (Marchese, 2012). 
que impactó especialmente en los grupos más empobrecidos de la sociedad, acrecentó la problemática habitacional ya existente y la tendencia hacia la desigualdad social, que se vio reflejada, incluso, en conflictos violentos, puesto que en ocasiones "... el territorio urbano se convierte en el campo de batalla de una guerra continua por el espacio, que a veces estalla en espectáculo público..." (Bauman, 1999: 33). Esta agudización de la lucha por el espacio urbano refleja cómo las asimetrías sociales se materializan en fragmentaciones socioespaciales, en las cuales las diferencias sociales tienden a yuxtaponerse cada vez más en el marco de una serie de procesos vinculados a la necesidad y a la búsqueda de espacios no solo físicos, sino también simbólicos.

La problemática habitacional de la CABA durante la década del noventa y principios del siglo XXI (es decir, en el período en que Argentina atravesó el pasaje de la modernidad a la posmodernidad) fue abordada por diferentes disciplinas (Flores, 1993; Cuenya, 2004; Fidel, 2004; Martínez, 2004/2005; entre otras). Estas investigaciones coinciden en que la población de la CABA fue sometida a una política urbana en la cual el Estado asumió una lógica económica casi empresarial, desligándose del plano social y de los conceptos de equidad e integración para orientarse hacia los intereses del mercado inmobiliario.

Si bien durante ese proceso las políticas habitacionales se deterioraron, la CABA (ciudad capital del territorio nacional) históricamente fue un foco de concentración de población en búsqueda de un futuro más próspero. La imposibilidad de lograr ese objetivo se hizo evidente a través del aumento de las villas y los asentamientos y de la aparición de los llamados "sin techo”. Hacia el año 2004, la problemática era crítica. Por ello, apoyándose en los artículos 14 bis de la Constitución de la Nación Argentina y 31 de la Constitución de la CABA, que enuncian que la vivienda digna es un derecho, la Legislatura de la
CABA (LCABA) declaró estado de emergencia habitacional por un plazo de tres años (Ley N 1408/ LCABA/04). En el año 2007, el plazo fue prorrogado por tres años más (Ley No 2472/LCABA/07) y, en el año 2010, la LCABA consideró que aún no se había solucionado la problemática e intentó prorrogar, nuevamente por otros tres años, el estado de emergencia, pero este intento fracasó en otras instancias legislativas.

Según los proyectos de ley que dieron origen a la Ley $N^{\circ}$ 1408, es decir, a la ley que declaró la emergencia en el año 2004, la crisis de la CABA en el plano habitacional poseía dos factores desencadenantes: primero, el colapso del sistema de ayuda social causado por el incremento del número de demandas habitacionales que este se veía obligado a canalizar; segundo, la ineficacia o, prácticamente, inexistencia de programas habitacionales orientados hacia el mediano y largo plazo.

Aunque la falta de políticas de mediano y largo plazo es un tema central en relación con la problemática habitacional y si bien se comparte la consideración de que los conflictos habitacionales se agudizaron, mientras que paralelamente crecía el mercado inmobiliario, la cuestión habitacional posee también otras características que deben ser pensadas críticamente. Los análisis estadísticos (modo en que, en general, se ha abordado la problemática) poco podrían decir de esas características, porque estas, por su propia naturaleza, precisan un abordaje cualitativo que posibilite ahondar en cómo los sujetos sociales construyen simbólicamente los espacios en que se desarrollan.

En ese marco, se propone que la reflexión en torno a los discursos de los diferentes sujetos sociales vinculados con la problemática habitacional puede iluminar sus aspectos cualitativos. Así, en este trabajo, se realizará un estudio sociodiscursivo crítico sobre la problemática habitacional de la CABA, que dará cuenta de las razones subyacentes relativas al fracaso de las políticas 
habitacionales y, en consecuencia, relacionadas con la llamada "reincidencia" de las personas en situación de pobreza en los programas habitacionales. Todo esto más allá de la buena voluntad de quienes se encargan de llevar adelante dichos programas, dado que no solo se necesita buena voluntad para solucionar las problemáticas sociales, sino, sobre todo, conocerlas en profundidad. A partir de lo expuesto, la hipótesis teórica ${ }^{3}$ en la que se apoya este trabajo es la siguiente: el espacio habitacional no es solo una entidad física, sino que es, fundamentalmente, una entidad simbólica, cuyas características (en general difíciles de asir) se plasman en propiedades discursivas que pueden rastrearse mediante el análisis del discurso.

El estudio de esas propiedades permitirá observar concretamente (en las formas lingüísticas) las diferencias que se presentan entre los discursos del GCABA y las historias de vida de sujetos en situación de pobreza, aportando una perspectiva crítica orientada hacia los componentes cualitativos de la problemática habitacional de la CABA. A su vez, un estudio de esta naturaleza dará cuenta de que el análisis del discurso, en tanto herramienta heurística, posibilita identificar, analizar y exponer detalladamente los componentes cualitativos de las problemáticas sociales. De esta forma, se establecen dos líneas centrales para el desarrollo de esta investigación:

- Las características de la problemática habitacional se evidencian a través de representaciones discursivas, construidas en torno a la categoría Espacio habitacional, que revelan cómo dicha problemática es experimentada por los sujetos en situación de pobreza y por el GCABA.
- El modo de jerarquizar la información da cuenta de cuáles son los componentes más relevantes de dicha problemática para cada uno de ellos.

Por último, el tema de esta investigación, que articula el análisis del discurso y la teoría social, pretende analizar no solo los discursos dominantes y los de los grupos excluidos, sino especialmente la intersección sociodiscursiva entre ambos.

\section{Marco teórico-metodológico}

El paradigma que guía esta investigación es el interpretativista (Guba y Lincoln, 1998), el marco teórico es el Análisis Crítico del Discurso (ACD) en sus vertientes europea (Fairclough, 1992; Van Dijk, 1993; Wodak, 2000) y latinoamericana (García da Silva, 2007; Pardo Abril, 2007; Pardo, 2008a, 2011; Ramalho y Resende, 2011) y la metodología utilizada es cualitativa e inductiva.

Se comparte con Fairclough (1992) la idea de que los discursos surgen de tres prácticas interrelacionadas: textual (PT), discursiva (PD) y social (PS). Sin embargo, siguiendo las críticas de Shi-xu (2007), que señalan que esas prácticas se representan como cajas dentro de cajas construyendo un esquema en el cual las relaciones sociales se plasman de un modo atomizado y dicotómico, se realizó una nueva propuesta que parte de dicho esquema (Marchese, 2012). En ella, los discursos de los sujetos sociales surgen de la conjunción de las tres prácticas y, a su vez, la PS se concibe como la intersección entre discursos de distintos sujetos sociales (véase la figura 1). El estudio de esa intersección permite relevar diferencias y similitudes respecto de los diversos sistemas de creencias que se materializan en los discursos que circulan en una sociedad 4 .

3 El concepto de hipótesis teórica (Pardo, 2011) se opone al de hipótesis a priori, es decir, una hipótesis teórica surge de investigaciones exploratorias previas vinculadas al tema que se pretende estudiar.

4 Se destaca que esta idea sí está presente en Fairclough (1992), aunque quizá no fue claramente representada en su esquema. 


\section{FIGURA 1}

Reformulación del esquema de Fairclough (1992)

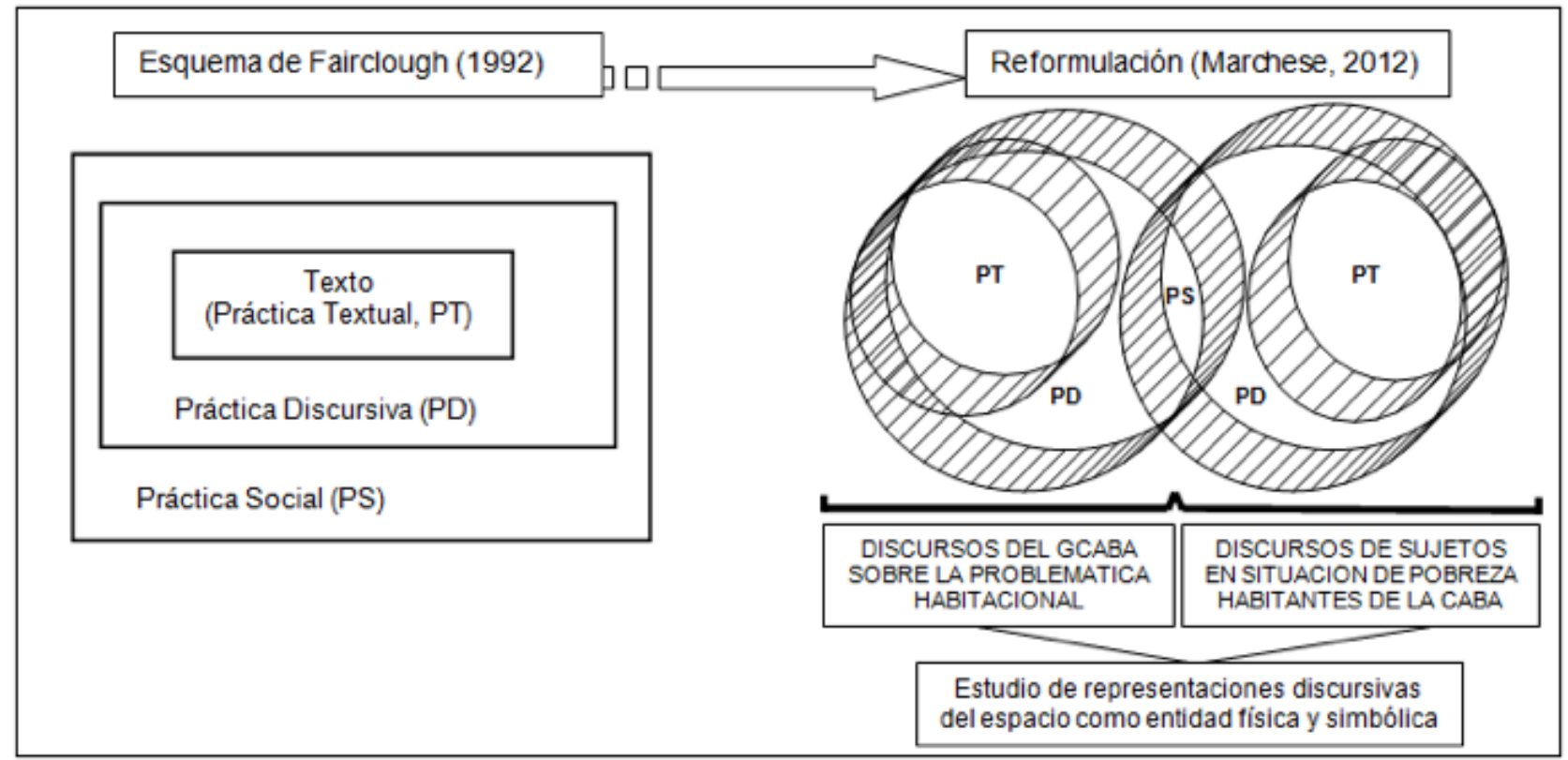

Para efectuar el análisis del discurso (AD), se utilizan las dos primeras fases del Método de abordajes lingüísticos convergentes para el $A D$ con perspectiva crítica (Marchese, 2011, 2012) ${ }^{5}$. Este método amplía el alcance analítico del Método sincrónico-diacrónico del análisis lingüístico de textos (Pardo, 2001, 2011), incorporándole el estudio de los roles temáticos y de la jerarquización y la tonalización de la información. El resultado es una herramienta heurística (en tanto técnica de indagación y descubrimiento), que posibilita analizar los discursos desde una perspectiva semántico-discursiva enfocada en el estudio del lenguaje en uso de un modo holístico y donde el análisis del plano sintáctico-gramatical es funcional a esa perspectiva. A continuación, se describirán las fases utilizadas para esta investigación y sus correspondientes operaciones analíticas.

\subsection{Fase 1: Método sincrónico-diacróni- co de análisis lingüístico de textos (Par- do, 2011) (operación: categorización)}

En esta fase, se relevan categorías gramaticalizadas y categorías semántico-discursivas, que permiten descubrir el modo en que los sujetos sociales categorizan el mundo que los rodea, imponiéndole un determinado orden. Las primeras son categorías lingüísticas que presentan alta frecuencia de aparición en diversos géneros: Operador pragmático (OP), Negación (Neg), Afirmación (Af), Hablante-Protagonista (H-P), ACtores, Nexos de Valor (Nv) $)^{6}$, Tiempo y Espacio. Las segundas son categorías lingüísticas que surgen específicamente en cada discurso. Este método incluye la Teoría de los desplazamientos categoriales. Esta posibilita estudiar el pasaje de un contenido semántico hacia otro, lo cual revela

5 El método posee cuatro fases ligadas a una serie de operaciones analíticas. Para este trabajo, se emplean las dos primeras.

6 Nexo de Valor se define como aquel elemento lingüístico que conecta (nexo) y que, a su vez, otorga una determinada valoración a esa conexión. Esta categoría puede corresponder tanto a un verbo o a un verboide como a una nominalización deverbal. 
las asociaciones cognitivas que se suceden en el devenir del discurso.

\subsection{Fase 2: Teoría de focalización de la información (operaciones: señalización, marcación y triangulación de datos)}

Esta teoría parte de las nociones de distribución de la información y de dinamismo comunicativo (Firbas, 1964) conjuntamente con el Principio de jerarquización de la información (Pardo, 2011), que incluye también la Tonalización de la información (Lavandera, 1986; Pardo, 2011). Mediante las nociones de Categoría focal y Zona focal (Marchese, 2011), se analizan cuáles son las categorías del método sincrónico-diacrónico focalizadas y cuáles son los recursos utilizados para reforzar y mitigar la información.

Categoría focal se define como aquella categoría que cierra una emisión. Para señalizar las categorías focales sobre el análisis ya efectuado (Fase 1), se emplea como bandera una combinación de letras inexistente en español: WF. Esto facilita la búsqueda de las categorías focales para realizar, posteriormente, la operación de triangulación de datos (cruce entre datos cualitativos y estadísticos). La Zona focal es aquella zona que se encuentra hacia el final de la emisión y que contiene la Categoría focal. Según como esté formulada la emisión, la Zona focal puede comenzar en la última preposición, el último conector, la última coma, el último pronombre relativo, el último adverbio o el último Nexo de Valor y suele estar conformada por la Categoría focal y las categorías penúltima y antepenúltima. Dado que esa es la zona de la emisión que posee mayor grado de dinamismo comunicativo, en ella se analiza la tonalización. La operación de marcación es la herramienta que incorpora este análisis. Dicha operación consiste en utilizar la cursiva y la negrita para marcar, respectivamente, mitigadores y reforzadores. Los primeros restan carga semántica al elemento que mitigan y los segundos cumplen la función contraria.
En el ejemplo 1, mediante el análisis de las siguientes emisiones (e) tomadas de una historia de vida del corpus de esta investigación: [Tener un empleo.] [Poder contar con ese empleo y vivir otra vez como antes.] [En realidad, nunca tuve un techo propio, pero tenía con que pagar mi techo y mi comida.], se puede apreciar una breve ilustración de la Fase 1 y la Fase 2. En la Fase 1, se observa que las categorías que aparecen en este fragmento son: Operador pragmático, $\mathrm{Ha}$ blante-Protagonista, Nexo de Valor, Tiempo, Espacio habitacional y Empleo. Dichas categorías se pueden estudiar: a) de modo sincrónico, esto es, en su ocurrencia sucesiva en las emisiones (indicado por las flechas horizontales), b) diacrónicamente, o sea, cómo se va cargando semánticamente una misma categoría (indicado por las flechas verticales) y c) a través de la Teoría de los desplazamientos categoriales, es decir, analizando cómo se desplazan los contenidos semánticos; por ejemplo, la aparición de la categoría Empleo habilita un desplazamiento discursivo hacia la categoría Espacio habitacional, lo cual revela una asociación cognitiva entre ambas categorías (indicado por las flechas oblicuas). Asimismo, la Fase 2 demuestra: a) que las categorías focales (señaladas con la bandera WF) son Tiempo, Espacio habitacional y Empleo y b) que el uso y la repetición del pronombre posesivo de primera persona mi (marcado con negrita) refuerza la carga semántica de la categoría Espacio habitacional y la orienta hacia el concepto de propiedad.

Finalmente, es importante resaltar que, como el método apunta a estudiar textos como unidades de análisis sociodiscursivas, para la interpretación de los datos del análisis se tienen presentes las características del género discursivo al que pertenecen los textos con el fin de evitar la sobreinterpretación.

\section{Corpus}

El corpus se compone, por un lado, de historias de vida (HDV) de sujetos adultos en situación 


\section{EJEMPLO 1}

Fase 1 y Fase 2 del Método de abordajes lingüísticos convergentes

\begin{tabular}{|c|c|c|c|c|c|}
\hline \multicolumn{6}{|c|}{ CATEGORÍAS LINGÜISTICAS } \\
\hline \multicolumn{5}{|c|}{ CATEGORİAS GRAMATICALIZADAS } & $\begin{array}{c}\text { CATEGORÍA } \\
\text { SEMÁNTICO-DISCURSIVA }\end{array}$ \\
\hline $\begin{array}{l}\text { OPERADOR } \\
\text { PRAGMÁTICO }\end{array}$ & $\begin{array}{c}\text { HABLANTE- } \\
\text { PROTAGONISTA }\end{array}$ & NEXO DE VALOR & TIEMPO & $\begin{array}{c}\text { ESPACIO } \\
\text { HABITACIONAL }\end{array}$ & EMPLEO \\
\hline & & [Tener & 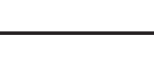 & 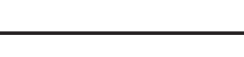 & $\rightarrow$ un empleo.] WF \\
\hline & & [Poder contar & 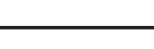 & 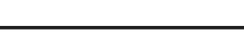 & $\rightarrow$ con ese empleo \\
\hline$y$ & & vivir & otra vez & & \\
\hline como & & & antes.] WF & & \\
\hline \multirow[t]{2}{*}{ [En realidad, } & & & nunca & & \\
\hline & & tuve & & un techo propio, & \\
\hline \multirow[t]{3}{*}{ pero } & & tenía & & & con que \\
\hline & & pagar & & & \\
\hline & mi & & & techo $\longleftarrow$ & \\
\hline y & mi & $\downarrow$ & & comida.] WF & $\downarrow$ \\
\hline \multicolumn{6}{|c|}{ CATEGORÍAS FOCALES } \\
\hline 0 & 0 & 0 & 1 & 1 & 1 \\
\hline
\end{tabular}

de pobreza habitantes de la CABA y, por otro, de discursos del GCABA vinculados al déficit habitacional.

En relación con las primeras, se identificaron tres situaciones: 1) quienes pernoctan en la vía pública o en paradores (estatales o religiosos), 2) quienes carecen de alojamiento fijo y residen temporalmente en hogares o en hoteles y 3 ) quienes poseen un lugar físico para habitar, pero viven en una situación precaria, por ejemplo, en las Ilamadas villas de emergencia. De acuerdo con estas tres situaciones, las HDV recolecta- das (desde el 2003 hasta el 2010) corresponden a sujetos que pernoctan en paradores y en la vía pública, que residen en hogares u hoteles y que viven en villas de emergencia o asentamientos urbanos. Las técnicas de recolección fueron observación-participante y grabación, con posterior toma de registro de lo observado en un diario etnográfico.

Respecto de los discursos del GCABA, el corpus abarca el período 1997-20087 y está compuesto por proyectos de ley, decretos ${ }^{8}$ y noticias publicadas por el GCABA, relacionados con

7 La diferencia entre el período que abarca el corpus de los discursos del GCABA y el correspondiente al corpus de las historias de vida no es arbitraria. Esa diferencia temporal permite analizar cuál fue el impacto de las acciones realizadas por el GCABA en la vida de las personas a las cuales estuvieron destinadas dichas acciones. Además, 1997 es el año en que la ciudad comenzó a funcionar como ciudad autónoma.

8 En el período 1997-2008, los documentos legales a través de los cuales se crearon programas de vivienda destinados a sujetos en situación de pobreza corresponden a decretos. 


\section{TABLA 1}

Diseño de la muestra teórica del corpus

\begin{tabular}{|c|c|c|c|c|}
\hline & \multicolumn{4}{|c|}{ Representaciones discursivas en torno a la categoría Espacio habitacional } \\
\hline \multirow{3}{*}{$\begin{array}{l}\text { FASE 1: Método sincrónico- } \\
\text { diacrónico de análisis } \\
\text { lingüístico de textos } \\
\text { FASE 2: Teoría de focalización } \\
\text { de la información }\end{array}$} & \multicolumn{3}{|c|}{$\begin{array}{c}\text { DISCURSOS DEL GCABA SOBRE LA } \\
\text { PROBLEMÁTICA HABITACIONAL (1997-2008) }\end{array}$} & \multirow{2}{*}{$\begin{array}{c}\text { DISCURSOS DE SUJETOS EN } \\
\text { SITUACIÓN DE POBREZA HABITANTES } \\
\text { DE LA CABA (2003-2010) } \\
\text { Historias de vida }\end{array}$} \\
\hline & Proyectos de ley & Decretos & Noticias & \\
\hline & 10 & 10 & 10 & 30 \\
\hline
\end{tabular}

la problemática habitacional y la pobreza. Mi experiencia laboral contribuyó a la recolección que se efectuó en los siguientes sitios: a) oficinas del Ministerio de Desarrollo Social del GCABA y del Instituto de Vivienda de la Ciudad, b) links Noticias y Boletín oficial del sitio web oficial del GCABA y c) sitio web oficial del Centro Documental de Información y Archivo Legislativo. En la tabla 1 se presenta el diseño de la muestra teórica del corpus y las herramientas lingüísticas de análisis.

\section{El espacio habitacional como entidad simbólica}

Para un analista crítico del discurso, estudiar el lenguaje en uso implica enfrentarse a una serie de fenómenos lingüísticos denominados, generalmente, como vicios del lenguaje, por ejemplo: anacolutos (inconsecuencias en la construcción del discurso), anfibologías (ambigüedades), barbarismos (palabras mal escritas o mal pronunciadas), impropiedades (faltas de propiedad en el uso de las palabras), neologismos (vocablos, acepciones o giros nuevos), pleonasmos (empleo de palabras innecesarias), redundancias (usos excesivos de palabras) y solecismos (faltas cometidas contra las normas de la sintaxis).
En la mayoría de las gramáticas descriptivas tradicionales, esos alejamientos respecto del uso recto son contemplados de modo tangencial. Sin embargo, en el análisis crítico del discurso, la situación es diferente, porque esos fenómenos lingüísticos revelan significados, partiendo de la base de que "Ios sujetos sociales transmiten significados tanto mediante lo que dicen como mediante la forma en que dicen lo que dicen" (Marchese, 2011: 13). Así, para una gramática tradicional, un anacoluto es una inconsecuencia en la construcción del discurso y el empleo de palabras innecesarias es un pleonasmo, mientras que para un analista crítico del discurso, un anacoluto es un indicio de que algo no puede ser expresado y un pleonasmo es una señal de que algo necesita ser reforzado.

En el corpus de este trabajo, uno de los alejamientos respecto del uso recto radica en lemas que las gramáticas definieron tradicionalmente como adverbios o pronombres de lugar (ahí, acá y donde) cuyos usos se vinculan al tiempo y no al espacio9. Tal como se aprecia en el ejemplo 2 (HDV de JO), el adverbio de lugar ahí no refiere a la categoría Espacio, sino a un momento puntual en la vida de JO.

9 Cabe resaltar que este uso está descripto en Bello y Cuervo (1948 [1847]). 


\section{EJEMPLO 2}

Transferencia de propiedades de la categoría Espacio a la categoría Tiempo

\begin{tabular}{|c|c|c|c|c|c|c|}
\hline OP. & NEG. & H-P. & NV & $\begin{array}{c}\text { ACTOR } \\
\text { (SOCIEDAD) }\end{array}$ & NV & TIEMPO \\
\hline \multirow[t]{3}{*}{ JO: } & & e86[Yo & & & & ya \\
\hline & & & estaba, & & & ya \\
\hline & & & $\begin{array}{c}\text { había hecho la } \\
\text { denuncia }\end{array}$ & $\begin{array}{c}\text { en la policía de } \\
\text { trabajo }\end{array}$ & & \\
\hline \multirow[t]{2}{*}{ y todo } & & & que & & & \\
\hline & & me & & & tenían en negro, & \\
\hline $\begin{array}{l}\text { no sé qué, y } \\
\text { entonces }\end{array}$ & & & & el abogado & $\begin{array}{l}\text { le agregó el } \\
\text { accidente }\end{array}$ & \\
\hline también porque & no & me & & & quisieron pagar.] & \\
\hline \multirow[t]{3}{*}{ e87[Entonces } & & & & & & ahí \\
\hline & & & & & automáticamente & \\
\hline & & me & & & echaron.] & \\
\hline
\end{tabular}

Para este trabajo, es relevante mencionar que esos elementos lingüísticos, que deberían referir a la categoría Espacio, pero que aquí se transfieren a la categoría Tiempo, dan cuenta de que ciertos momentos nucleares para la construcción de la identidad de los sujetos se instauran como espacios simbólicos, es decir, como lugares o puntos de anclaje de la memoria.

De modo semejante, se observaron desplazamientos discursivos (indicado con flecha en el ejemplo 3) entre las categorías Espacio-habitacional y Hablante-Protagonista (H-P), mediante los cuales se transfieren a esta última categoría elementos lingüísticos que podrían referir a la primera. El ejemplo 3 (HDV de RE) demuestra cómo las propiedades de la categoría Espacio habitacional (hogar de ancianos) se transfieren a la categoría H-P. En este caso, RE no utiliza la frase preposicional de ancianos, la cual modificaría (de forma indirecta) al sustantivo hogar, sino que convierte esa frase preposicional en un adjetivo (anciano) que refiere a la categoría $H-P$, es decir, a su propio self. Este ejemplo da cuenta del impacto negativo que genera una derivación, efectuada por el GCABA, a un hogar de ancianos y pone en evidencia el hecho de que el espacio no es meramente una entidad física, sino que esa entidad física repercute sobre la construcción simbólica de la identidad de los sujetos sociales. En otras palabras, el ejemplo demuestra que, cognitivamente, el espacio habitacional no está escindido del sujeto. Por el contrario, forma parte constitutiva y sustancial de él.

\section{EJEMPLO 3}

Transferencia de propiedades desde la categoría Espacio habitacional hacia la categoría H-P

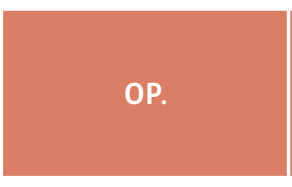

NEG.

RE:

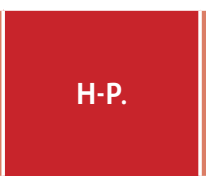

e59[Yo
NV

NV

(DEL ACTOR GCABA)
ESPACIO

HABITACIONAL

(HOGAR DE

ANCIANOS) 


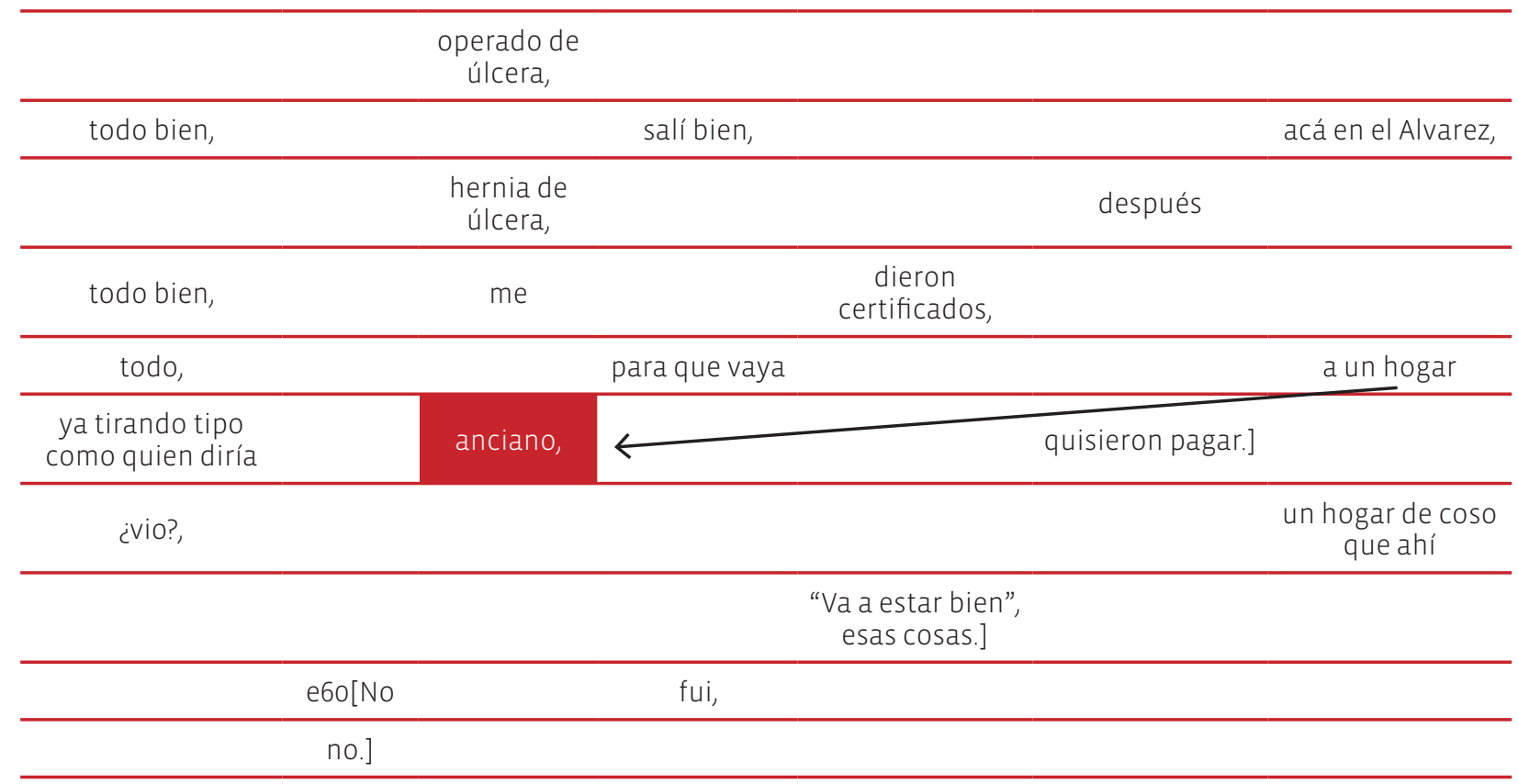

El ejemplo anterior conduce a otro aspecto a destacar ligado a la construcción de representaciones discursivas en torno a la categoría Espacio habitacional, dado que dicha construcción presenta diferencias en los corpus analizados. El estudio diacrónico de esa categoría en los discursos del GCABA manifiesta que se construye en relación con: a) los ítems léxicos hogar, hotel, parador, casa y vivienda y b) desplazamientos discursivos recurrentes (indicados con flechas en los ejemplos) desde la categoría Espacio habitacional hacia la categoría Tiempo donde se observan adjetivos relacionales con matiz temporal restrictivo, como provisorio, transitorio, temporario, nocturno y temporal. A continuación, se presentan dos ejemplos representativos (ejemplo 4 y ejemplo 5):

\section{EJEMPLO 4}

Desplazamiento desde la categoría Espacio habitacional hacia el adjetivo nocturno

\begin{tabular}{|c|c|c|c|c|c|}
\hline \multicolumn{6}{|c|}{ NOTA INFORMATIVA INSTITUCIONAL 07-06-06 } \\
\hline OP. & $\begin{array}{c}\mathrm{H}-\mathrm{P} . \\
\text { (GCABA) }\end{array}$ & NV & $\begin{array}{c}\text { ACTOR } \\
\text { (PERSONAS EN SITUACIÓN } \\
\text { DE RIESGO SOCIAL) }\end{array}$ & TIEMPO & $\begin{array}{l}\text { ESPACIO HABITACIONAL } \\
\text { (PARADOR NOCTURNO) }\end{array}$ \\
\hline & e3[Se & inauguró & & el primer & parador \\
\hline & & & & nocturno & \\
\hline \multicolumn{6}{|c|}{ para mujeres solas } \\
\hline y & \multicolumn{5}{|c|}{ madres con hijos] } \\
\hline
\end{tabular}




\section{EJEMPLO 5}

Desplazamiento desde la categoría Espacio habitacional hacia el adjetivo transitoria

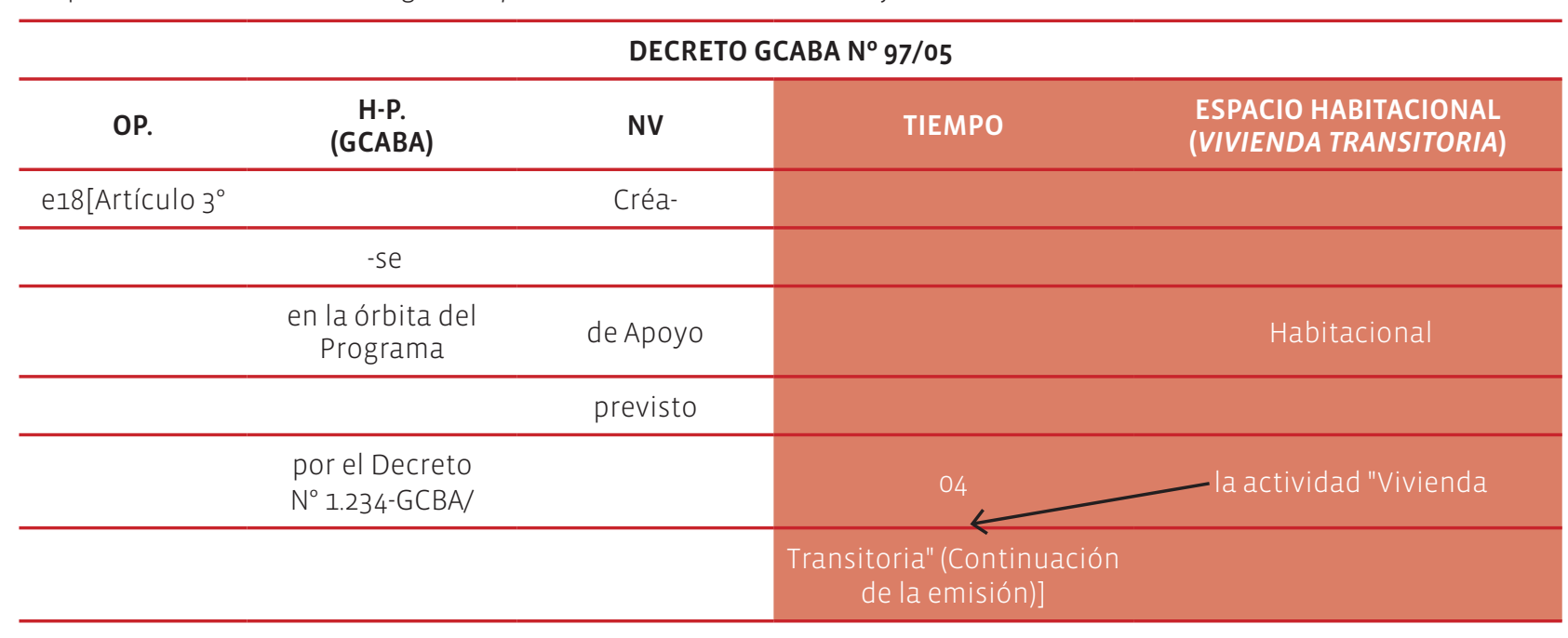

De esa forma, la representación discursiva de esos espacios habitacionales es la de alojamientos temporales o transitorios (véase ejemplo 6). En este sentido, cabe recordar que los adjetivos relacionales modifican al sustantivo caracterizándolo en relación con su pertenencia a un determinado ámbito. Así, el espacio habitacional queda restringido al ámbito de lo transitorio o de lo temporal, ya sea que se trate de paradores, hoteles, hogares, casas o viviendas.

\section{EJEMPLO 6}

Desplazamiento desde la categoría Espacio habitacional hacia el adjetivo transitorio

\begin{tabular}{|c|c|c|c|c|}
\hline \multicolumn{5}{|c|}{ PROYECTO DE LEY LCABA Nº $1149 / 06$} \\
\hline OP. & $\begin{array}{c}\mathrm{H}-\mathrm{P} . \\
(\mathrm{GCABA})\end{array}$ & NV & TIEMPO & $\begin{array}{l}\text { ESPACIO HABITACIONAL } \\
\text { (CASAS ABIERTAS) }\end{array}$ \\
\hline \multirow[t]{4}{*}{ e6[Artículo $3^{\circ}$.- } & & Son objetivos & & \\
\hline & de la presente Ley:] & e7[a) Ofrecer & & - alojamiento \\
\hline & & & transitorio, & servicio de duchas, \\
\hline & & & & ropa limpia \\
\hline y & & & & otras prestaciones básicas;] \\
\hline
\end{tabular}

Ahora bien, en las HDV, esa construcción no se encuentra reflejada, sino más bien refractada a modo de un eco distorsionado. Esta situación se materializa discursivamente en desplazamientos entre la categoría Espacio-situación de calle y la categoría Espacio habitacional. Estos desplazamientos comienzan en la categoría
Espacio-situación de calle, atraviesan la categoría Espacio habitacional y vuelven hacia la categoría Espacio-situación de calle, tal como ejemplifica la HDV de SA (ejemplo 7). Ese ejemplo también manifiesta cómo, efectivamente, ocurre la llamada "reincidencia" de las personas en situación de pobreza en los programas 
habitacionales, puesto que el alojamiento transitorio o temporario resulta, para ellos, solo un paliativo frente a su problema para acceder a una vivienda.

\section{EJEMPLO 7}

Desplazamiento entre la categoría Espacio-situación de calle y la categoría Espacio habitacional
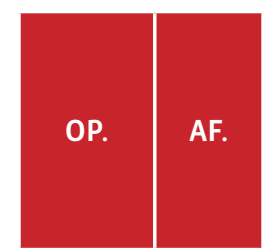

SA:
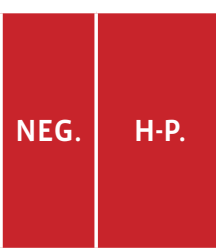

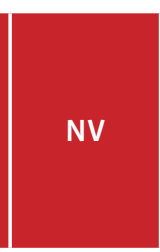

e26[Vivía

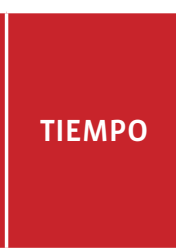

ESPACIO HABITACIONAL (HOGAR DEL EJÉRCITO DE SALVACIÓN Y HOTELES)

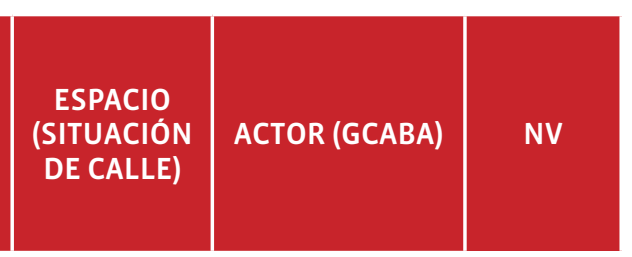

en la calle,

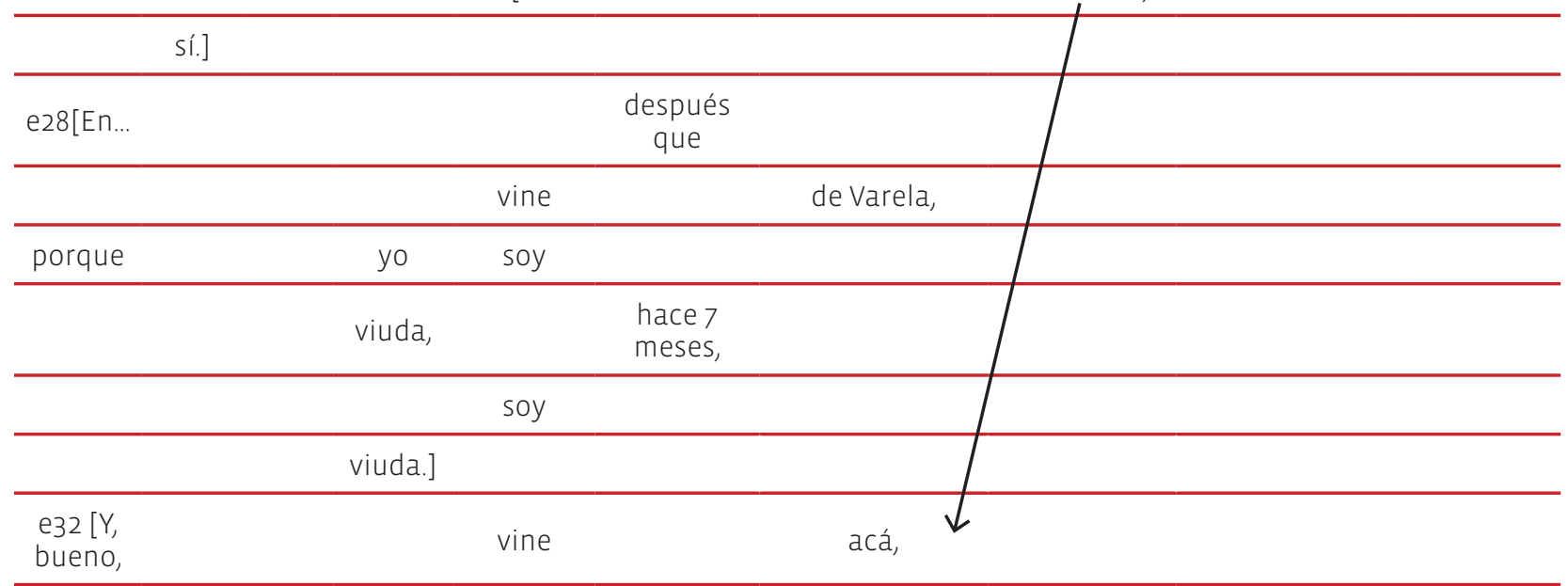

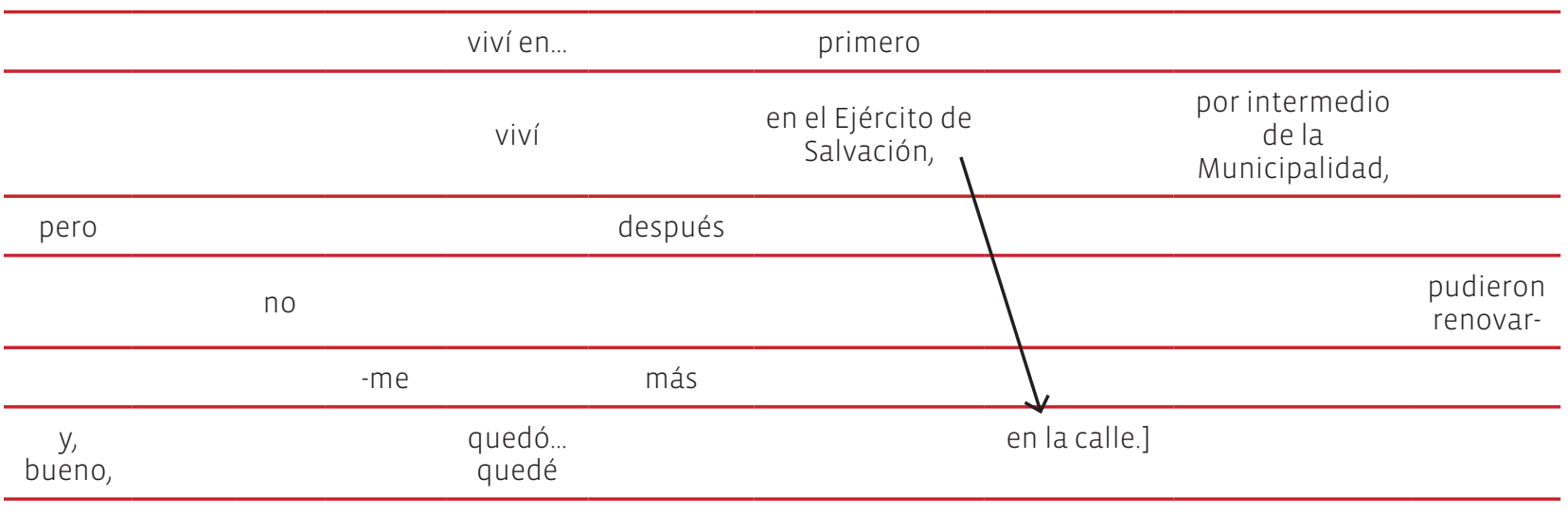

Otra diferencia sustancial entre las HDV y los discursos del GCABA radica en que, en las primeras, surgen otras representaciones ligadas al espacio habitacional. Éstas se vinculan con los ítems léxicos casa y vivienda. A diferencia de los discursos del GCABA, en las HDV, esas representaciones no se construyen asociadas a adjetivos relacionales con matiz temporal restrictivo, sino, por el contrario, a dos nociones: permanencia y propiedad.

El ejemplo 8, que también corresponde a la HDV de SA, expresa el vínculo entre el espacio habitacional y la noción de permanencia. De modo similar al ejemplo 3 (HDV de RE), se observa aquí cómo se transfieren elementos lingüísticos desde la categoría Espacio habitacional hacia la catego- 
ría H-P (adjetivo quieta). La selección de ese adjetivo, en lugar de algún otro concordado gramaticalmente con el sustantivo lugar (categoría Espacio habitacional), da cuenta de cómo las propiedades del espacio se desplazan hacia los sujetos y de que el espacio no es una entidad escindida del sujeto, sino que lo constituye. Además, este ejemplo evidencia la oposición entre las categorías Espacio habitacional (hogares y hoteles) y la categoría Espacio habitacional (lugar fijo).

\section{EJEMPLO 8}

Transferencia de propiedades desde la categoría Espacio habitacional hacia la categoría H-P
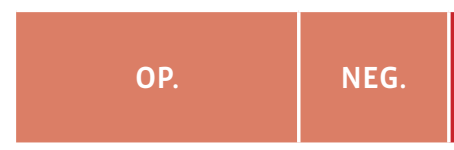

SA:

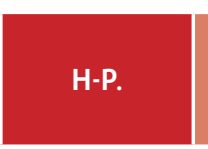

NV
ESPACIO HABITACIONAL (HOGAR DEL EJÉRCITO DE SALVACIÓN Y HOTELES)
ESPACIO HABITACIONAL (LUGAR FIJO)

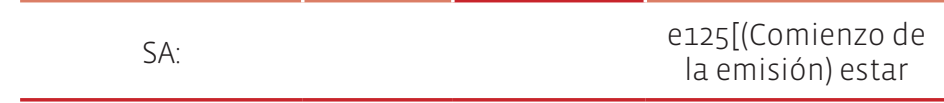

e125[(Comienzo de

más

tranquila,

\begin{tabular}{|c|c|c|c|c|}
\hline $\mathrm{y}$ & & tener & & un lugar \\
\hline & & estar & así & \\
\hline como tipo ¿viste & $\begin{array}{l}\text { los gitanos } \\
\text { que }\end{array}$ & van & $\begin{array}{c}\text { de un lado para otro con } \\
\text { todos los hoteles, }\end{array}$ & \\
\hline
\end{tabular}

viste?]

Asimismo, en las HDV, los adjetivos relacionados con la construcción de la representación discursiva casa contrastan significativamente con los que aparecen en los discursos del GCABA. Los ejemplos 9 y 10 evidencian dicho contraste.
En ellos, el ítem léxico casa no se liga a adjetivos relacionales con matiz temporal restrictivo, sino a pronombres personales posesivos (mi) que orientan ese ítem léxico hacia el concepto de propiedad.

\section{EJEMPLO 9}

Uso de pronombres personales posesivos

\begin{tabular}{|c|c|c|c|c|}
\hline OP. & $H-P$. & NV & $\begin{array}{c}\text { ACTOR } \\
\text { (FAMILIA) }\end{array}$ & $\begin{array}{l}\text { ESPACIO HABITACIONAL } \\
\text { (CASA) }\end{array}$ \\
\hline \multirow[t]{5}{*}{ RO: } & e151[Me & gustaría & & \\
\hline & & estar & con & \\
\hline & $\mathrm{mi}$ & & esposa & \\
\hline & mis & & hjjos, & en \\
\hline & $\mathrm{mi}$ & & & casa, \\
\hline
\end{tabular}




\section{EJEMPLO 10}

Uso de pronombres personales posesivos

\begin{tabular}{|c|c|c|c|c|c|c|c|}
\hline OP. & NEG. & H-P. & NV & ACTOR (OS) & NV & TIEMPO & $\begin{array}{l}\text { ESPACIO HABITACIONAL } \\
\text { (CASA) }\end{array}$ \\
\hline \multirow[t]{2}{*}{ I: e161[¿Y } & & & & vos & pensás que sos & & \\
\hline & & & & feliz & & ahora & \\
\hline 0 & no?] & & & & & & \\
\hline OS: & e162[No & & & & & & \\
\hline \multirow{3}{*}{ y } & no, & feliz, & & & & & \\
\hline & no, & feliz & sería & & & & \\
\hline & & & estando & & & & \\
\hline \multirow[t]{5}{*}{ ponele } & & & & & & & en \\
\hline & & $\mathrm{mi}$ & & & & & casa \\
\hline & & & & & & & con agua fría, \\
\hline & & & & & & & agua caliente, \\
\hline & & & mirando & & & & $\begin{array}{l}\text { la televisión, (Continuación } \\
\text { de la emisión).] }\end{array}$ \\
\hline
\end{tabular}

Esa asociación entre espacio habitacional y permanencia y espacio habitacional y propiedad, que se manifiesta discursivamente en las HDV, no está profundizada ni desarrollada en los discursos del GCABA. Por el contrario, el espacio habitacional se construye vinculado a las representaciones discursivas vivienda, casa, parador, hogar, etc., tal como han sido descriptas a través de los ejemplos 4, 5 y 6.

Hasta aquí, mediante datos lingüísticos concretos, se ha demostrado que la construcción de representaciones discursivas ligadas a la categoría Espacio habitacional difiere en los corpus estudiados. Ahora bien, el análisis también evidenció que esa diferencia se expresa en los componentes de la problemática habitacional que resultan más relevantes en cada corpus. Así, las HDV focalizan, fundamentalmente, la carencia de vivienda, mientras que los discursos del GCABA tienden a focalizar las consecuencias que dicha problemática genera sobre la ciudad.
En las HDV, las categorías focales con mayor frecuencia de aparición son: a) Nv correspondiente a la categoría Hablante-Protagonista (66,67\% de las HDV presentan esta categoría como categoría focal predominante) y b) Espacio habitacional (casa) (25\% de las HDV presentan esta categoría como categoría focal predominante). El dato (a) se debe a la naturaleza del género HDV, en el cual predomina la automanifestación del self, mientras que el dato (b) da cuenta de que lo que resulta más relevante para los sujetos (es decir, lo que se focaliza) es la vivienda, específicamente, la carencia de ella.

En el ejemplo 11 (HDV de AC), se observa esa focalización. La zona focal de la ezg presenta desplazamientos en los que intervienen las categorías Negación, Nv, Hablante-Protagonista y Espacio habitacional, que queda ubicada como categoría focal. Primero, la categoría Negación (adverbio de negación reforzador no) se desplaza hacia la categoría Nv (proceso relacional 
posesivo tengo). Luego, desde esta categoría, el discurso avanza hacia la categoría Hablante-Protagonista, donde comienzan frases nominales formadas por el pronombre personal posesivo de primera persona (mi). Desde este pronombre, que también funciona como un reforzador ${ }^{10}$, se produce otro desplazamiento hasta la categoría Espacio habitacional, que queda ubicada discursivamente como categoría focal de la emisión (señalada con la bandera WF) donde, nuevamente, aparecen reforzadores (sustantivo lugarr). Además, estas coocurrencias se refuerzan por repetición. En el ejemplo, los desplazamientos se indican con flechas, los refuerzos se marcan con negrita y la zona focal está resaltada con color.

\section{EJEMPLO 11}

Focalización de la carencia de vivienda en las HDV

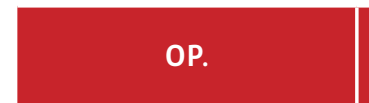

AC: e29[(Comienzo de la emisión) pero

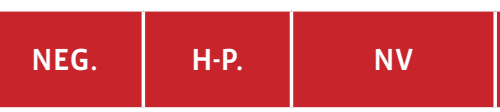

continúo estando

\section{ESPACIO (SITUACIÓN DE CALLE)}

en la calle,

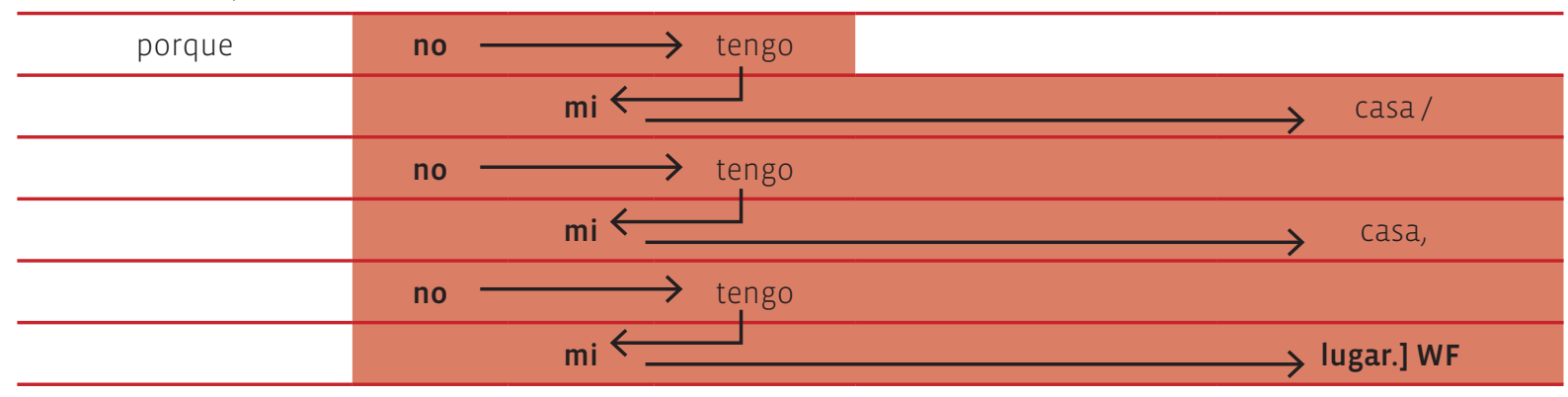

Frente a esa distribución de categorías focales en las HDV, la distribución en los discursos del GCABA manifiesta que la carencia de vivienda no es el elemento más relevante de la problemática habitacional. Estos discursos tienden a focalizar cómo esa situación impacta sobre la CABA. Así, la categoría Espacio urbano posee alta frecuenta de aparición como categoría focal (el 50\% de los discursos posee esta categoría como categoría focal predominante) y se compone de una serie de propiedades discursivas que la construyen como un espacio-problema o un espacio en conflicto.
En las zonas focales de las emisiones, se relevaron refuerzos que contribuyen a esa construcción. Entre los más destacados, se encuentran (los refuerzos se marcan con negrita, las zonas focales se resaltan con color y las categorías focales se señalan con la bandera WF): a) frases nominales y preposicionales cuyos núcleos son los sustantivos emergencia, crisis, riesgo y conflicto (ejemplo 12), b) adjetivos relacionales (social y habitacional) y adjetivos calificativos evaluativos (como grande y grave), que acompañan a los sustantivos ejemplificados en (12) (ejemplo 13) y c) adjetivos determinativos numerales cardinales (como 28 y 16.000) (ejemplo 14).

10 Frente a otras opciones paradigmáticas posibles, como el artículo indeterminado una, el pronombre posesivo de primera persona es reforzador. 


\section{EJEMPLO 12}

Focalización de la categoría Espacio urbano

\begin{tabular}{|c|c|c|c|c|}
\hline \multicolumn{5}{|c|}{ NOTA INFORMATIVA INSTITUCIONAL 10-09-07 } \\
\hline $\begin{array}{l}\mathrm{H}-\mathrm{P} . \\
(\mathrm{GCABA})\end{array}$ & NV & $\begin{array}{c}\text { ACTORES } \\
\text { (DAMNIFICADOS) }\end{array}$ & TIEMPO & $\begin{array}{c}\text { ESPACIO URBANO } \\
\text { (CIUDAD EN EMERGENCIA) }\end{array}$ \\
\hline & e16[Cabe señalar que & & desde fines de 2006 & \\
\hline se & cuenta & & & \\
\hline con el Centro & & de Evacuados, & & \\
\hline que & habilitó & & & \\
\hline $\begin{array}{l}\text { la totalidad de } \\
\text { sus vacantes }\end{array}$ & para la atención & & & de la emergencia.] WF \\
\hline
\end{tabular}

\section{EJEMPLO 13}

Focalización de la categoría Espacio urbano

\begin{tabular}{|c|c|c|c|c|c|}
\hline \multicolumn{6}{|c|}{ PROYECTO DE LEY LCABA Nº 2065/02 } \\
\hline $\begin{array}{c}\text { H-P. } \\
\text { (GCABA) }\end{array}$ & NV & $\begin{array}{l}\text { ACTOR (PROGRAMA } \\
\text { PROPUESTO) }\end{array}$ & NV & TIEMPO & $\begin{array}{c}\text { ESPACIO URBANO } \\
\text { (CIUDAD EN EMERGENCIA) }\end{array}$ \\
\hline \multirow[t]{2}{*}{$\begin{array}{l}\text { e29[(Comienzo de la } \\
\text { emisión) una norma que }\end{array}$} & brinde & $\begin{array}{c}\text { nuevas } \\
\text { herramientas }\end{array}$ & para & la inmediata & \\
\hline & & & solución & & $\begin{array}{l}\text { de este grave conflicto } \\
\text { social.] WF }\end{array}$ \\
\hline
\end{tabular}

\section{EJEMPLO 14}

Focalización de la categoría Espacio urbano

\begin{tabular}{|c|c|c|c|c|c|c|c|}
\hline \multicolumn{8}{|c|}{ NOTA INFORMATIVA INSTITUCIONAL 15-09-04 } \\
\hline OP. & $\begin{array}{c}\mathrm{H}-\mathrm{P} . \\
(\mathrm{GCABA})\end{array}$ & NV & $\begin{array}{c}\text { ACTOR } \\
\text { (POBLACIÓN DE } \\
\text { VILLA 20) }\end{array}$ & NV & TIEMPO & $\begin{array}{l}\text { ESPACIO URBANO } \\
\text { (CIUDAD EN } \\
\text { EMERGENCIA) }\end{array}$ & $\begin{array}{c}\text { SOLUCIÓN } \\
\text { PROPUESTA } \\
\text { (NUEVAS OBRAS) }\end{array}$ \\
\hline \multicolumn{8}{|c|}{ e14[Durante } \\
\hline \multicolumn{8}{|c|}{$\begin{array}{l}\text { el acto de } \\
\text { inauguración, }\end{array}$} \\
\hline & Ibarra & realizó & & & & & \\
\hline \multirow[t]{3}{*}{ además } & & anuncios & & & & & de nuevas obras \\
\hline & & & & & & en la villa 20, que & \\
\hline & & cuenta & $\begin{array}{c}\text { con una } \\
\text { población de } \\
\mathbf{1 6 . 0 0 0} \text { personas, }\end{array}$ & ubicadas & & $\begin{array}{c}\text { en alrededor de } \mathbf{2} 8 \\
\text { manzanas.] WF }\end{array}$ & \\
\hline
\end{tabular}


En suma, los datos relevados mediante el análisis crítico de los discursos del GCABA ponen de manifiesto que el Espacio habitacional es construido como un fin en sí mismo. De aquí que las representaciones discursivas de un parador, un hogar, un hotel y de una casa o vivienda sean construidas de modo similar. Específicamente, como alojamientos temporales o transitorios. Esta situación se debe a que, como se ha demostrado lingüísticamente, el foco de la problemática habitacional para el GCABA es el impacto que la falta de vivienda genera sobre la ciudad. En estos discursos, lo que se tiende a focalizar es la categoría Espacio urbano (ciudad en emergencia), no la categoría Espacio habitacional.

Por el contrario, en las HDV, las representaciones discursivas casa y vivienda no se construyen del mismo modo que las de hotel, parador y hogar, dado que las primeras están fuertemente ligadas a las nociones de permanencia y de propiedad. Esa relación se apoya en el hecho de que, en estos discursos, el Espacio habitacional (casa o vivienda) se construye como el espacio físico que permite concretar otros objetivos. Poder poseer y permanecer en una vivienda no es aquí un fin en sí mismo, sino el factor de posibilidad básico para proyectar la vida. Por ello, en las HDV, las representaciones discursivas casa o vivienda no son fines en sí mismos, sino medios

El contraste desarrollado en los párrafos anteriores se evidencia en la comparación entre el ejemplo 15 (HDV de HE) y el ejemplo 16 (discursos del GCABA). En el primero, se observa que la emisión de HE no concluye en tener un lugar, sino que se proyecta, a través del complemento introducido por la preposición para, hacia otro objetivo: hacer mi familia, que trasciende la casa o la vivienda en sí mismas, pero para el cual estas son condición de posibilidad. De ahí proviene la importancia simbólica que la casa o la vivienda posee para los sujetos sociales y de ahí, también, puede inferirse el impacto que implica su pérdida o la imposibilidad de acceder a ella.

Ahora bien, el ejemplo 16 (que reproduce el ejemplo 5) demuestra que, en los discursos del GCABA, ese aspecto simbólico de la categoría Espacio habitacional está ausente, porque las representaciones casa y vivienda se construyen como fines en sí mismos, es decir, como meros albergues transitorios para protegerse de los elementos del medio ambiente. En estos discursos, la construcción de esas representaciones no se asocia a complementos introducidos por preposiciones que indiquen metas a futuro, sino que esos signos se cierran sobre sí mismos.

\section{EJEMPLO 15}

Representación discursiva de la vivienda: medio

\begin{tabular}{cccc}
\hline OP. & H-P. & NV & $\begin{array}{c}\text { ESPACIO HABITACIONAL } \\
\text { (CASA Y FAMILIA PROPIOS) }\end{array}$ \\
\hline HE: e190[Ojo, & & tener & un lugar, \\
\hline pero también & & implica que & el lugar \\
\hline & me & sirva & \\
\hline & para hacer & familia.] WF
\end{tabular}




\section{EJEMPLO 16}

Representación discursiva de la vivienda: fin en sí mismo

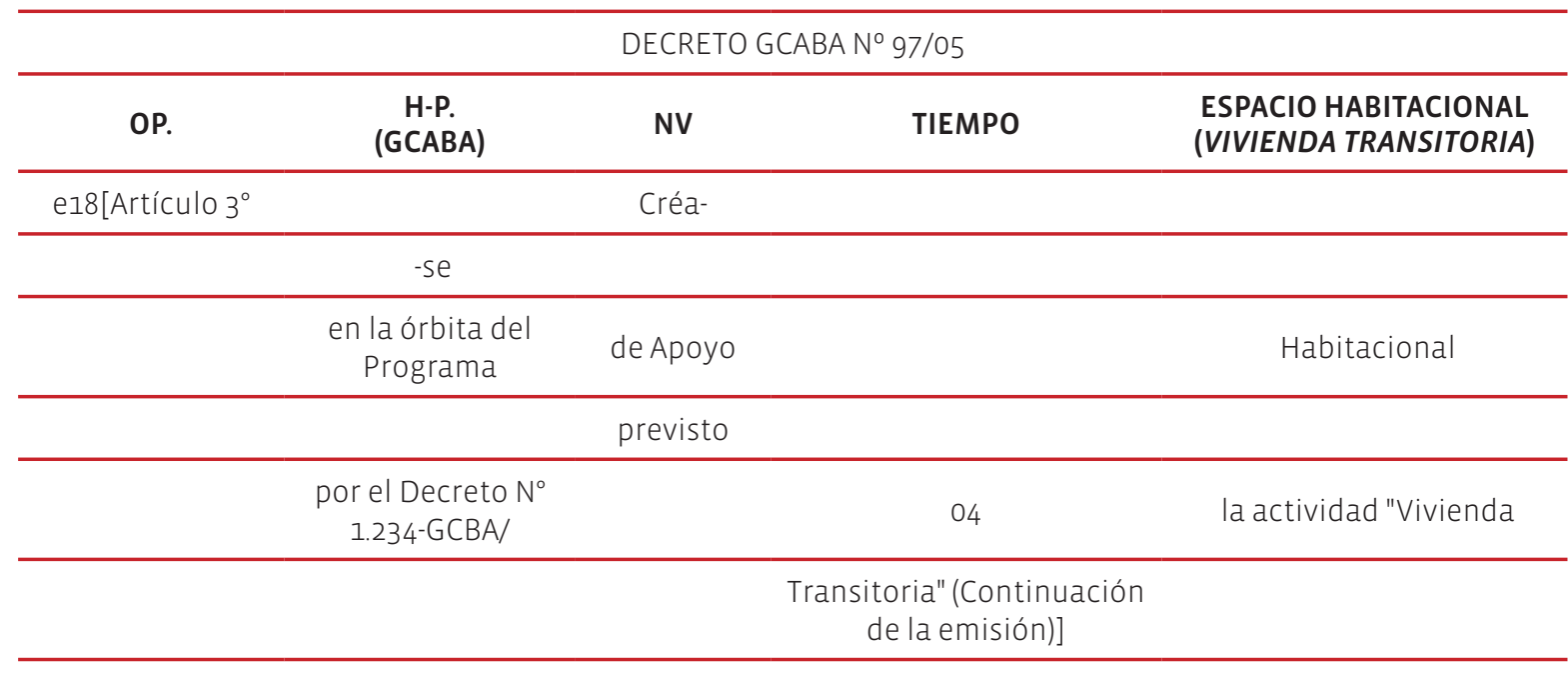

\section{Conclusiones}

El análisis de los discursos del GCABA y de las HDV aportó datos lingüísticos concretos que revelan una serie de diferencias entre ellos, relativas a la construcción de representaciones discursivas en torno a la categoría Espacio habitacional. Este análisis puede colaborar a explicar las causas profundas y las consecuencias sociales vinculadas con la problemática de la carencia de vivienda en la CABA, con el fin de que estos datos de naturaleza predominantemente cualitativa sean tenidos en cuenta para la elaboración de políticas públicas. En este sentido, las características del espacio habitacional como entidad física y simbólica se plasmaron en propiedades discursivas que pudieron ser rastreadas y evidenciadas de modo concreto mediante el análisis del discurso. Así, se demostró, también, que este modo de análisis, en tanto herramienta heurística, posibilita identificar, analizar y exponer detalladamente los componentes cualitativos de las problemáticas sociales.

En primer lugar, los datos manifiestan que la problemática posee raíces más profundas que las mencionadas en los proyectos que originaron la ley de emergencia habitacional (Ley $\mathrm{N}^{\circ}$
1408). Esos proyectos argumentaban que la crisis de la CABA en el plano habitacional poseía dos factores desencadenantes: a) el colapso del sistema de ayuda social causado por el incremento del número de demandas habitacionales que este se veía obligado a canalizar y b) la ineficacia o, prácticamente, inexistencia de programas habitacionales orientados hacia el mediano y largo plazo. Si bien no se niega que estos factores pueden influir, el análisis discursivo evidenció que existe un factor clave más profundo. Este puede resumirse en que las manifestaciones discursivas acerca del espacio habitacional realizadas por los sujetos en situación de pobreza habitantes de la CABA no se encuentran reflejadas en los discursos del GCABA.

En segundo lugar, los datos dan cuenta de que ese factor clave podría estar inherentemente relacionado con el fracaso sistemático de las acciones aplicadas para intentar resolver la problemática habitacional. Lo que los discursos del GCABA omiten es que el espacio no es solo una entidad física, sino que es, fundamentalmente, una entidad simbólica, puesto que los espacios por los que atraviesa un sujeto en su vida, a su vez, lo atraviesan y, así, operan en la construc- 
ción de su identidad individual y social. En este sentido, el espacio habitacional opera como condición de posibilidad, física y simbólica, para la proyección de otros objetivos (formar una familia, comenzar estudios, etc.). De aquí puede inferirse el impacto simbólico del hecho de que, frente a la carencia de vivienda, el GCABA proponga alojamientos transitorios, siguiendo un patrón discursivo que emparda las representaciones parador, hogar, hotel y casa o vivienda, como si fueran una misma cosa. Esta situación discursiva manifiesta que no se tiene presente que las personas afectadas por la problemática habitacional no se enfrentan solo a la búsqueda de espacios físicos para habitar, sino también a la necesidad de espacios simbólicos que les permitan desarrollarse como miembros de la sociedad.

\section{Bibliografía citada}

Bauman, Zygmunt, 1999: La globalización. Consecuencias humanas, Buenos Aires: Fondo de Cultura Económica de la Argentina S.A.

Bello, Andrés y Rufino José Cuervo, 1948 [1847]: Gramática de la lengua castellana, Buenos Aires: Anaconda.

Cuenya, Beatriz, 2004: "Grandes proyectos y teorías sobre la nueva política urbana en la era de la globalización. Reflexiones a partir de la experiencia de la ciudad de Buenos Aires" en Beatriz Cuenya, Carlos Fidel e Hilda Herzer (coords.): Fragmentos sociales: problemas urbanos de la Argentina, Buenos Aires: Siglo XXI, 89-110.

Demajo Meseguer, Lucía, 2011: "Barrios cerrados en ciudades latinoamericanas", Revista de Estudios Urbanos y Ciencias Sociales I (1), 151-60.

FalRclough, Norman, 1992: Discourse and Social Change, Cambridge: Polity Press in association with Blackwell Publisher.

Fidel, Carlos, 2004: "Orientación y peculiaridades de la política económica, social y habitacional en la Argentina. La década del 90" en Beatriz CuenYA, Carlos Fidel e Hilda Herzer (coords.): Fragmentos sociales: problemas urbanos de la Argentina, Buenos Aires: Siglo XXI, 75-87.

FIRBAS, Jan, 1964: "On defining the theme in functional sentence analysis", Travaux Linguistiques de Prague 1, 267-80.

Flores, Susana, 1993: Construcción del espacio urbano. Socialización-privatización, Buenos Aires: Centro Editor de América Latina.

García d Silva, Denize Elena, 2007: "Critical Discourse Analysis and the functional bases of language" en Leila Barbara y Tony Berber Sardinha (eds.): Proceedings of the 33rd International Systemic Functional Congress, São Paulo: PUCSP, 932-49.

García da Silva, Denize Elena y Claudia Gabriela D’ Angelo, 2011: "Representações sociais da pobreza em textos midiáticos e multimodais", ponencia presentada en el IX Congresso Latino-Americano de Estudos do Discurso: Um marco histórico de integração acadêmica. Discursos da américa latina: vozes, sentidos e identidades.

GubA, Egon e Yvonna Lincoln, 1998: "Competing Paradigms in Qualitative Research" en Norman Denzin e Yvonna Lincoln (eds.): The Landscape of Qualitative Research. Theories and Issues, Thousand Oaks: Sage, 195-220.

Lavandera, Beatriz, 1986: "Decir y aludir: una propuesta metodológica", Cuadernos del Instituto de Lingüística 1 (1), 3-14.

MARCHESE, Mariana Carolina, 2011: El texto como unidad de análisis socio-discursiva. Una propuesta a partir del Método sincrónico-diacrónico de análisis lingüístico de textos, Buenos Aires: Tersites.

MarCHeSe, Mariana Carolina, 2012: Análisis crítico de la representación discursiva de la vivienda en historias de vida de sujetos en situación de pobreza urbana y en discursos del Estado. El déficit habitacional en la Ciudad Autónoma de Buenos 
Aires en la posmodernidad. Tesis Doctoral, Facultad de Filosofía y Letras, Universidad de Buenos Aires.

Martínez, Clarisa, 2004/2005: "Juegos de reconocimiento del derecho al espacio urbano en la Ciudad de Buenos Aires. El caso de la política de radicación de villas", Revista Lavboratorio. Estudios sobre el Cambio Estructural y la Desigualdad Social 6 (16), 26-31.

Montecino, Lésmer (ed.), 2010: Discurso, pobreza y exclusión en América Latina, Santiago: Cuarto Propio.

Moura, Rosa, 2011: "Grandes projetos urbanos e planejamento territorial", Boletim Campineiro de Geografía 1 (1), 7-30.

PARDo, María Laura, 2001: "La expresión discursiva del mandato. Análisis lingüístico del texto de la ley de reforma laboral argentina”, Revista Iberoamericana de Discurso y Sociedad. Lenguaje en contexto desde una perspectiva crítica y multidisciplinaria 3 (2), 117-37.

Pardo, María Laura, 2008a: "Una metodología para la investigación lingüística del discurso" en María Laura PARDo (ed.): El discurso sobre la pobreza en América Latina, Santiago: Frasis, 55-78. PARDo, María Laura, 2008b: "La estetización y espectacularización de la pobreza: análisis crítico del discurso posmoderno televisivo en la Argentina” en Tulio Ortiz y María Laura PARdo (coords.): Desigualdades sociales y Estado. Un estudio multidisciplinar desde la posmodernidad, Buenos Aires: Departamento de Publicaciones, Facultad de Derecho, Universidad de Buenos Aires у Аз Plus, 139-64.

PARDo, María Laura, 2011: Teoría y metodología de la investigación lingüística. Método sincrónicodiacrónico de análisis lingüístico de textos, Buenos Aires: Tersites.

Pardo Abril, Neyla Graciela, 2007: Cómo hacer Análisis Crítico del Discurso. Una perspectiva Latinoamericana, Santiago: Frasis.
Pradilla Cobos, Emilio, 2010 : "Mundialización neoliberal, cambios urbanos y políticas estatales en América Latina", Cadernos Metrópole 12 (24), 50733.

Ramalho, Viviane y Viviane de Melo Resende, 2011: Análise de discurso (para a) crítica: o texto como material de pesquisa, Campinas: Pontes.

Resende, Viviane de Melo y Mariana Carolina MARCHESE, 2011: "São as pessoas pobrezitas de espírito que agudizam a pobreza dos pobres': análise discursiva crítica de testemunho publicado na revista Cais - o método sincrônico-diacrônico", Cadernos de Linguagem e Sociedade (Papers on Languaje and Society) 12 (2), 150-78.

SHI-XU, 2007: "Reconstruyendo los paradigmas orientales de los estudios del discurso", Revista Latinoamericana de Estudios del Discurso 7 (1), 79-94.

Van DIJK, Teun, 1993: "Principles of Critical Discourse Analysis", Discourse \& Society. An International Journal for the Study of Discourse and Communication in their Social, Political and Cultural Contexts 4 (2), 249-83.

WACQUANT, Loïc, 2007: "La estigmatización territorial en la edad de la marginalidad avanzada", Ciências Sociais Unisinos 43 (3), 193-9.

Wodak, Ruth, 2000: "¿La Sociolingüística necesita una Teoría Social? Nuevas perspectivas en Análisis Crítico del Discurso", Revista Iberoamericana de Discurso y Sociedad. Lenguaje en contexto desde una perspectiva crítica y multidisciplinaria 2 (3), $123-47$. 